\title{
Impact of regional aspects on the assessment of natural gas consumption by industrial facilities
}

\author{
Vladimir Koksharov ${ }^{1,2}$, and Irina Kirshina ${ }^{1,3,}{ }^{*}$ \\ ${ }^{1}$ FSAEI HE "Ural Federal University named after the first President of Russia B.N. Yeltsin", \\ Sverdlovsk region, Yekaterinburg, Kominterna street, 11, Russia \\ ${ }^{2}$ FSBEI HE "Ural State University of Railway Transport", Sverdlovsk Region, Yekaterinburg, Mira \\ street, 19, Russia \\ ${ }^{3}$ I.M. Gubkin Russian State Oil and Gas University (National Research University), Moscow, \\ Leninsky prospect, 65, block 1, Russia
}

\begin{abstract}
The gas industry in the modern Russian economy is of great significance both at the at the national level as a whole and on the scale of a particular region. The task of ensuring reliable power supply to the population is enshrined in the framework of the Energy Strategy of Russia for the period until 2035. Gasification of the regions of Russia is one of the large-scale and socially significant areas of work in the domestic market, within the framework of which the task of providing energy to consumers is being solved. At the same time, the current problem of slowing down the demand for natural gas by industrial consumers in the country should be noted. An attempt to explain the behavior of natural gas demand determined the relevance, purpose and objectives of the study. The purpose of the study conducted by the authors is to study the peculiarities of the influence of regional aspects on the assessment of natural gas consumption by industrial facilities. The authors analyzed the complex of existing problems, and proposed a unified classification of natural gas consumption factors in order to solve this problem. The classification of natural gas consumption factors proposed by the authors can be considered in the development of General schemes of gas supply and gasification of the constituent entities of the Russian Federation, programs for the development of gas supply and gasification of regions.
\end{abstract}

\section{Introduction}

The gas industry in the modern Russian economy is of great significance both at the at the national level as a whole and on the scale of a particular region. The gas supply system of Russia is a key pillar of the national economy, on the reliable and effective functioning of which its viability depends. The gas industry occupies $8 \%$ of the structure of gross domestic product, provides a significant part of the country's income $[1,2]$.

\footnotetext{
* Corresponding author: i.kirshina@yandex.ru
} 
In 2019, gas production in Russia amounted to 737.5 billion $\mathrm{m}^{3}$, natural gas consumption in the Russian market has been fluctuating at the level of 450-460 billion $\mathrm{m}^{3}$ over the past 10 years $[3,4]$.

The further increase in gas consumption is associated with the development of gas chemistry, an increase in the use of gas as a motor fuel, as well as the continued implementation of gasification programs in the regions, which, taking into account recent trends, assumes an increase in rates. The total consumption of natural gas is significantly increased by the presence of enterprises in the region of the energy complex [5]. The purpose of the work carried out is to study the peculiarities of the influence of regional aspects on the assessment of natural gas consumption by industrial facilities. The authors carried out the complex analysis of existing problems, and proposed a unified classification of natural gas consumption factors in order to solve this problem.

\section{Materials and methods}

The working hypothesis of the study is based on the provision that the natural gas demand from the industrial sector of the economy is formed under the influence of various groups of factors (gas supply source, financial and economic conditions for the development of gas supply systems, etc.). The research process was based on various theoretical and empirical scientific methods. Scientific information and scientific achievements were collected and systematized within the array of issues under consideration.

The present study involves a fairly extensive volume of theory, to the development of which many scientists and specialists have made a notable contribution. The study of theoretical issues of forecasting gas demand in the constituent entities of the Russian Federation was carried out by Zamergrad V.E., Marfutov L.A., Antonov N.V., Chicherov E.A.

The problems of the formation of regional fuel and energy balances and their assessment, the development of models for the forecast of energy consumption, much attention is paid in the works of Okhorzin Yu.A., Sennova E.V., Melekhin E.S. The authors also considered the development of energy strategies, the formation of programs for the development of energy in the country and regions.

The study of the Russian and European gas market was carried out by Privalov N.G., Cetiner S.M., Fechtelkotter P., Legatt M. and others.

\section{Results and discussion}

Gas consumption in each country can be divided into several groups. Traditional consumers are the electric power sector, industry and the domestic household and commercial sectors. The use of gas to generate electricity is the most capacious direction in gas consumption (Figure 1) [6, 7]. In industry, gas is used for household needs of factories, for heating, energy generation, and equipment functioning. 


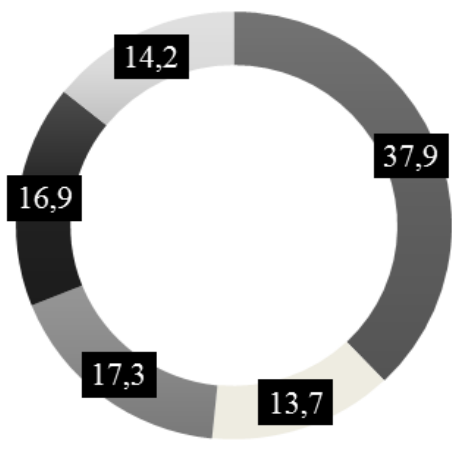

- Power engineering

Other

Utilities sector

- Industry

Population

Fig. 1. Structure of natural gas consumption in Russia, \%

Natural gas prices in Russia are among the lowest in the world, while the availability of gas as a resource, including in the east of the country, is limited by the lack of infrastructure $[8,9]$.

The existing price leads to the actual suppression and absence of inter-fuel competition and, as a consequence, a significant distortion in the energy balance of Russia. The share of gas in it is increasing, and reached $60 \%$, and in the European part of the country it exceeds $70 \%$.

At the stage of development of General schemes of gas supply and gasification of regions of the Russian Federation it is required to assess the demand for gas depending on a wide range of factors determining the pace, structure, volumes of gasification of consumers in the territory [2].

A comprehensive form of representing the energy consumption of a territorial entity, including the city, is the fuel and energy balances (hereinafter - FEB). The form of energy balance allows to obtain in the form of tables and graphs the complete quantitative correspondence of supply, distribution and consumption of all types of energy resources, measured in the same accounting units [5].

The balance is established between the stages of production, processing, transformation, transport, distribution, storage and final use of energy resources in the country as a whole, region, subject of the Russian Federation or in the context of main economic activities. Reflecting in one table all important energy connections and proportions: the role of individual energy resources in the energy balance, the role of individual sectors in the consumption of individual energy resources - the energy balance provides an opportunity to obtain a complete and connected energy picture of the region/city [2, 10, 11].

Alongside with that, taking into account trends in the economic and social development of territories, including the fuel and energy complex, it can be the basis for forecasting the demand and supply of energy resources in the region or a municipal formation, an instrument for a future-oriented outlook of the fuel and energy complex, energy threats and ways to overcome them $[2,5]$.

The development of FEB allows:

- to analyze and predict energy efficiency indicators;

- to develop and monitor energy efficiency programmes; regions;

- to develop energy strategies, energy development programmes of the country and

- to form shortage of energy resources; 
- to carry out an analysis of the dynamics, factors and causes of changes in energy consumption of the gross regional product (hereinafter referred to as GRP) and energy intensity of GRP, including the use of decomposition techniques;

- to develop models for forecasting energy consumption coupled with models for forecasting the development of the region's economy, etc.

- to show the role of individual energy resources in the energy balance;

- to show the role of individual sectors in the consumption of individual energy resources;

- to reflect the full relationship between different power supply systems and energy consumption [9].

In accordance with the Energy Strategy of Russia for the period until 2035, among the challenges to the spatial development of the Russian Federation it is important to note the imbalance in the location of energy production and consumption centers, which gives rise to an unprecedented large and constantly growing volume of the most expensive land transportation of fuel over long distances. Nowadays there is a high concentration of economic growth and resource consumption in the European part of the country, which has exceeded 60 per cent of the country's energy consumption. Concurrently, the production of energy resources is shifting to the polar regions of the country with an increase in the length of pipeline systems.

According to the scenario conditions of the energy development of the Russian Federation, fossil fuels will remain the basis of national energy with a gradual increase in the share of renewable energy sources in the fuel and energy balance [12].

In order to describe the factors limiting the consumption of natural gas by industrial consumers in the regions of the Russian Federation, the following classification is proposed, which corresponds to the technological principle of organizing gas supply from the field to the consumer. With reference to this principle, the following categories and groups of factors are formed (Figure 2).

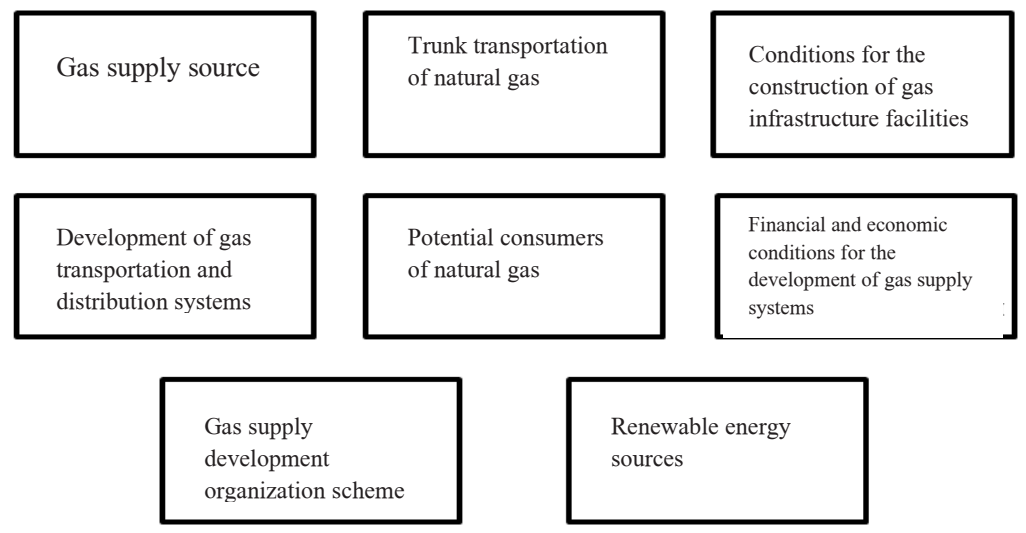

Fig. 2. Factors of limitation of natural gas consumption by industrial facilities

The classification of regions, taking into account the proposed system of factors, consists in indicating for each region information on certain types of problems of gas supply development. Note that the specific problems of the region in this category may differ from each other, as well as the ways in which they can be surmounted.

Let's consider a more detailed classification in each of the formed categories of problems of natural gas consumption by enterprises. Such a detailed classification allows you to more accurately describe the existing problems of gas supply development and form effective 
measures to solve them. It should be noted that the definition of detailed problems may require additional questionnaire surveys in the regions, in particular with the help of gas companies in the region [13].

In order to identify the existence of certain problems in the constituent entities of the Russian Federation in accordance with the formed groups of problems, we will specify the factors in each group:

1. The source of gas supply:

1.1 lack of natural gas resources in the region,

1.2 lack of a solution on the timing of the start of development and bringing the facility to the required level of gas production,

1.3 the distance of potential consumers of the region from the existing natural gas resource,

1.4 limitation on the current gas supply resource.

Geographical extent of the region is one of the components of the territorial specifics of the regional market. The development of gas transportation infrastructure is of particular importance in those regions that have a significant extent. Each regional economic and social system has a center in which real and functional elements are concentrated. Large territorial spaces create imbalances in satisfaction of demand: on the one hand, production centers, as large gas consumers, are provided with gas transportation infrastructure; on the other hand, provision of gas supplies to the population of the periphery entails an increase in the length of gas transportation networks with low gas consumption [14, 15].

So the Far Eastern Federal District (hereinafter - the FEFD) is characterized by a weak development of gas supply and gasification. In five regions of the district there is no gas supply with natural gas (Amur Region, Magadan Region, Jewish Autonomous Region, Trans-Baikal Territory and the Republic of Buryatia). In two regions of the district (Chukotka Autonomous Distric and Primorsky Territory), although there is a gas supply system with network natural gas, to date, only industrial enterprises, utility facilities and thermal power facilities are gas consumers. There is also no natural gas supply in 2 regions of the Siberian Federal District (hereinafter - SFD) (the Republic of Khakassia and Tyva) [2, 4].

2. Main transportation of natural gas:

2.1 reconstruction of the main gas pipeline (further MGP) or restoration of design characteristics is required,

2.2 reconstruction of gas pipeline branches (further - GPB) and gas distribution stations (further - GDS) or restoration of their design characteristics is required,

2.3 new construction, MGP, GPB and GDS is required.

The prospects for the development of the gas supply system may be related to the reconstruction and technical re-equipment of GDS and GPB, which have a high load and/or unsatisfactory technical condition, as well as the creation of technical opportunity for the implementation of investment projects, including the construction of new gas supply sources - GDS and GPB, if necessary. These measures must be implemented simultaneously with the readiness of consumers to receive gas.

Such aspects are characteristic of the Central Federal District. In view of this, the main tasks of gas companies in the region should be to ensure the reliability of gas supply to consumers by keeping them operational, performing the necessary amount of capital and preventive repairs.

3. Conditions for the construction of gas infrastructure facilities:

3.1 complications due to the topographic features of construction site (mountain conditions),

3.2 complications due to the hydrographic characteristics of the construction site (river crossings, crossings of water reservoirs, canals, etc.),

3.3 complications due to natural barriers (road network, railway), 
3.4 complications due to ground features (rocks, marshland),

3.5 complications due to the passage of routes in protected areas and areas with restrictions on activities,

3.6 complications related to construction restrictions,

3.7 lack of infrastructure (distance from production of materials and equipment, difficulties in organizing construction, transportation of materials).

4. Balanced, systemic development of gas transport and distribution systems:

4.1 development not according to the General Scheme,

4.2 conflict of economic interests (several gas companies in the region operating in the same territory),

4.3 gas supply facilities on the balance sheet of the consumer,

4.4 imbalance in the construction of technologically connected gas supply facilities.

5. Potential natural gas consumers:

5.1 overstatement of prospective volumes, lack of responsibility for the declared volumes, including for their realization,

5.2 focal location of potential consumers (small need, remoteness from each other),

5.3 failure to comply with the time limits for the commissioning of consumption objects and sales volumes,

5.4 uncertainty about the implementation timeline of the gas demand,

5.5 lack of purchasing power and assistance from local authorities to connect consumers,

5.6 debts for consumed gas.

The continuous expansion of the regional market capacity and quality parameters is a characteristic feature of its development. Market capacity is a possible volume of sales of goods in the domestic market, determined by the size of purchasing power of consumers at a given price level. In turn, the volume of consumption depends on the level of gasification of the region - the availability of gas transportation systems for all potential consumers, as well as on the individual needs of consumers that form the general regional structure of gas consumption $[7,9]$.

The SFD and the FEFD are characterized by a low distribution density of potential industrial customers with small volumes of potential gas consumption.

We should mention the largest outstanding gas bills from the subjects of the North Caucasus Federal District, which is the main factor that reduces the attractiveness of gas supply projects in this district.

6. Financial and economic conditions for the development of gas supply systems:

6.1 lack of funding for the development of gasification from the federal budget;

6.2 lack of efficient gas supply projects for consumers in the region for investors;

6.3 investment premium restrictions for gas transportation through gas distribution networks for the development of gasification;

6.4 the final price of gas for consumers is higher than the price of local fuels.

The FEFD has significant reserves of coal, hydrocarbons, hydroelectric power plants with significant volumes of installed capacity (for example, the Kolyma hydroelectric power station in the Magadan region, which generates about $95 \%$ of electricity in the region). With this in mind, natural gas cannot compete with coal and hydraulic resources. The development of gas supply to these regions of the district can be considered as the implementation of socially beneficial projects with government assistance.

7. Scheme of organization of gas supply development:

7.1 lack of funds for implementation of regional (interregional) gasification programs.

7.2 lack of a gas supply development and gasification program for Gazprom PJSC in the region.

7.3 lack of gas development articles of expenditure in regional budgets; 
7.4 lack of a government decision on a scheme for the development of gas supply, including recognition of the inexpediency of developing such a method of energy supply.

8. Renewable energy

The introduction and state support of renewable energy sources also occupies the place of gas in the electrical generation market. All the described factors adversely affect gas consumption, gas stations are not loaded at full capacity and the growth prospects are very obscure. And yet, the introduction of new energy-efficient equipment can greatly affect demand.

The focus on energy conservation in production will not contribute to increasing gas consumption, but at the same time, environmental policies stimulate the consumption of gas in production.

With stable gas prices in the future, it is possible to increase its consumption due to the refusal of coal and oil products. It is worth noting that despite the reduction of production, it will be quite difficult to abandon the use of gas in industry, since gas is the main fuel in the operation of modern equipment in most industrial processes $[7,11]$.

\section{Conclusions}

Most of these factors are related to the imperfection of regulations, which restrains the development of gasification of the constituent entities of the Russian Federation. Apart from that, it should be kept in mind that the design and construction of gas supply facilities is carried out at peak design consumption indicators, which correspond to the full-scale implementation of gas supply schemes with the connection of all declared consumers, taking into account their maximum gas offtake. Simultaneously, taking into account the unevenness of gas consumption by most categories of consumers (gas is used for heating in winter), objects are used (loaded) in the annual cross-section, as a rule, not higher than $25-30 \%$ of the potential capacity. And consumers pay not for the used power of the system, but for the actually consumed gas, taking into account their real need in accordance with weather condition.

Thus, the working hypothesis put forward at the beginning of the study is proved: the demand for natural gas from the industrial sector of the economy is formed under the influence of various groups of regional factors. This study can be further used in the formation of approaches to effective planning for the development of gas supply and gasification of the regions of the country in the short, medium and long term. The classification of proposed natural gas consumption factors can be considered in the development of General schemes of gas supply and gasification of the constituent entities of the Russian Federation, programs for the development of gas supply and gasification of regions.

Future studies on this topic may be aimed at creating a list of factors affecting the consumption of natural gas with the indication of problems based on numerical indicators of the economic situation, gas supply and gasification of the region, the carrying-out of programs, official cost-of-living statistics of the population and other socio-economic indicators of the region. It is possible to indicate not only the problem, but also the level of its impact on the system as a whole.

\section{References}

1. N. G. Privalov, T. B. Li, News of the Ural State University of Economics, 5 (61), 110 (2015) 
2. V.E. Zamergrad, L.A. Marfutov, Yu.A. Okhorzin, E.V. Sennova, Gas Industry, 10, 45 (2009)

3. L.D. Gitelman, V.V. Dobrodey, M.V. Kozhevnikov, Economy of the region, 16(4), 1208 (2020)

4. N.V. Antonov, E.A. Chicherov, Energosberezhenie, 5, 40 (2020)

5. A.P. Dziuba, I.A. Solovyova, Vestnik Volga State University, 3, Economics. Ecology, 20(1), 78 (2018)

6. E.S. Melekhin, E.V. Morozova, S.E. Fedorova, Problems of the economy and management of the oil and gas complex, 6, 15 (2018)

7. E.S. Melekhin, S.E. Fedorova, Problems of the economy and management of the oil and gas complex, 4, 22 (2019)

8. I.A. Kirshina, S.E. Fedorova, Problems of economics and management of the oil and gas complex, 4 (184), 77 (2020)

9. A.A. Makarov, F.V. Veselov, A.S. Makarova, T.V. Novikova, T.G. Pankrushina, Thermal Power Industry, 11, 40 (2017)

10. V.F. Dunaev, V.A. Shpakov, V.N. Lyndin, Economics of enterprises (organizations) of the oil and gas industry, 330 (2015)

11. A.L. Novoselov, I.Yu. Novoselova, I.M. Potravny, E.S. Melekhin, Resource economy: textbook and practicum for undergraduate and graduate, 343 (2019)

12. A.A. Makarov, T.A. Mitrova, F.V. Veselov, A.A. Galkina, V.A. Kulagin, Power system, 10, 5 (2017)

13. S.V. Orekhova, G.N. Pryakhin, F.Ya. Legotin, Vestnik of the Chelyabinsk State University, 18 (347), 103 (2014)

14. A.F. Andreev, E.P. Samokhvalova, A.A. Pelmeneva, E.V. Burykina, Fundamentals of economy and organization of oil and gas production: textbook for students of higher education institutions, 320 (2014)

15. N.V. Pakhomova, V.O. Titov, Bulletin of St. Petersburg State University, 2, 143 (2015) 